\title{
A DESSUBJETIVAÇÃO DO TRABALHO: O HOMEM COMO OBJETO DA TECNOLOGIA*
}

\author{
André Guimarães Augusto ${ }^{* *}$
}

\begin{abstract}
RESUMO Este trabalho visa a apresentar uma reflexão crítica sobre a tecnologia a partir da obra de Marx. A tecnologia é compreendida como forma de organização do processo de trabalho sob as relações de produção capitalista. O processo de trabalho capitalista é apreendido como um duplo processo de objetivação e dessubjetivação do trabalho, sendo este último resultado da aplicação ao processo de produção das ciências que tem o homem como objeto.
\end{abstract}

Palavras-chave: tecnologia; trabalho; ciência

Código JEL: B 51; M 54

\section{UNSUBJECTIVATION OF WORK: MEN AS TECHNOLOGY OBJECT}

ABSTRACT The purpose of this paper is to present a critical account of technology on the grounds of Marx's work. Technology is understood as a form of organization of work process under capitalist production relations. Capitalist work process is understood as a dual process of objectivation and unsubjectivation of work. Unsubjectivation of work is the result of application in work process of sciences that have man in its many dimensions as object.

Key words: technology; work; science

\footnotetext{
* Artigo enviado em 24 de maio de 2007 e aprovado em 8 de junho de 2009.

** Professor adjunto do Departamento de Economia da Universidade Federal Fluminense, e-mail: andre@economia.uff.br
} 


\section{INTRODUÇÃO}

A sociedade contemporânea apresenta imensos avanços na capacidade do homem em transformar a natureza. Essa transformação não teria sido possível sem o acúmulo de descobertas científicas e as transformações no processo de trabalho. O pensamento crítico, no entanto, não deve se limitar ao reconhecimento da ampliação das capacidades humanas na transformação da natureza. É preciso ir além e desvendar sob as maravilhas da tecnologia as relações sociais que lhe dão forma e conteúdo. Com esse objetivo, a obra de Marx é o ponto de partida para toda reflexão crítica sobre a tecnologia, o que constitui o objetivo deste trabalho.

O texto se inicia com a apresentação sucinta do conceito de tecnologia em Marx a partir da relação entre forças produtivas e relações de produção. Em seguida procura-se desfazer o fetiche tecnológico apreendendo a tecnologia como parte das relações sociais capitalistas. As transformações no processo de trabalho e a evolução da tecnologia são compreendidas como um processo de objetivação e dessubjetivação do trabalho, sendo este último resultado da colocação do homem como objeto da tecnologia.

\section{FORÇAS PRODUTIVAS, RELAÇõES DE PRODUÇÃO E TECNOLOGIA}

As características gerais do trabalho constituem o ponto de partida para compreender a tecnologia em Marx. O trabalho consiste em uma atividade na qual a humanidade transforma a natureza de acordo com uma finalidade, movida pelas suas necessidades (Marx, 2002). Para atingir a finalidade a humanidade mobiliza suas pontecialidades para transformação da natureza, agindo sobre as relações de causalidade presentes nesta. Nesse processo, a humanidade cria meios de produção que aumentam sua capacidade de transformação da natureza.

Essa descrição sumária das características do processo de trabalho permite uma primeira aproximação do conceito de forças produtivas: as potencialidades que permitem à humanidade transformar a natureza. As forças produtivas não se reduzem a uma lista de meios de produção; além dos instrumentos de produção e objetos de trabalho, o conceito de forças produtivas abrange, dentre outros, as habilidades dos trabalhadores e o conheci- 
mento das relações causais da natureza. Mas esse conceito geral consiste apenas em uma primeira aproximação; é preciso observar outras dimensões do conceito de forças produtivas.

O processo de trabalho em suas características gerais é apreendido por Marx como uma relação entre a humanidade e a natureza. Mas a humanidade genérica é apenas uma abstração; a humanidade só existe como conjunto das relações sociais que os homens concretos estabelecem na reprodução de sua vida (Marx, 1987a). É preciso, portanto, considerar esse aspecto no conceito de forças produtivas; em outras palavras, trata-se de incorporar o elemento histórico no conceito de forças produtivas e assim superar uma falsa dicotomia.

É esse elemento histórico que está ausente no determinismo tecnológico. O determinismo tecnológico pode ser definido como a autonomia da tecnologia em face das relações sociais em seu funcionamento; a tecnologia seguiria um desenvolvimento unilinear e universal, devendo os diferentes domínios da vida social se adaptar ao estado das forças produtivas/tecnologia (Feenberg, 1992). Ao mesmo tempo, a autonomia da tecnologia em face das relações sociais implica sua neutralidade.

Um exemplo do determinismo das forças produtivas é encontrado em Cohen (1989). O conceito de forças produtivas é apreendido por ele como derivado unicamente da relação entre humanidade e natureza, sendo as relações de produção determinadas pelas forças produtivas. De acordo com Cohen, "el carácter de la superestructura se explica por la naturaleza de su base, y este último se explica por la naturaleza de las fuerzas productivas" (Cohen, 1989, p. 24). Nessa interpretação, as forças produtivas — resultantes da relação entre humanidade e natureza — seriam um dado para as relações de produção - referente às relações entre os homens. As relações de produção, por sua vez, seriam apenas uma forma de desenvolver e, a partir de certo ponto, limitar as forças produtivas, um elemento condicionador, mas não determinante:

(...) las relaciones de producción predominantes en una sociedade, lo son debido a que constituyen relaciones que hacen avanzar el desarrollo de las fuerzas productivas. El nível de las fuerzas productivas determina qué relaciones de producción surgirán en este nivel $y$, en consecuencia, se obtiene relaciones de ese tipo (Cohen, 1989, p. 25). 
Trata-se, portanto, de uma dicotomia entre forças produtivas e relações de produção, apreendidas de forma unilateral e em uma relação de causalidade determinista. A interpretação determinista das forças produtivas é tão arraigada que é capaz de alinhar um fundador do marxismo analítico Cohen - aos teóricos do regime soviético. Embora partindo de uma argumentação diferente, o marxismo soviético aderiu, na prática, à tese do determinismo e da neutralidade da tecnologia, adotando métodos de produção capitalista:

The police of "quantitative" developments of capitalist-type of productive forces from wich Stalin expected the production of "material bases of communism" have (literally) bound labour. This error (essencialy identical to technological determinism) has existed since the beggining of Russian Revolution; since then the workers' oposition has been oposed on this point to Lenin, who mechanically imported Taylorism and the individual direction of factories (Lipietz, 1993, p. 109).

Ou ainda de acordo com Feenberg:

(...) the Soviet regime adopted a typical instrumentalist position on technology, using and importing it as though it were a neutral tool. This is the significance of Lenin's famous remark that communism is "electrification plus soviets" (Feenberg, 2002, p. 11).

Não serão exploradas aqui todas as consequências do determinismo tecnológico; procura-se apenas ressaltar o contraste com a interpretação proposta neste trabalho. Se as forças produtivas se referem à relação entre humanidade e natureza e se a humanidade só existe como conjunto das relações sociais, as forças produtivas determinam e são determinadas pelas relações de produção. Em outras palavras, a relação entre forças produtivas e relações de produção não pode ser apreendida como uma relação de determinação unilateral, mas, sim, uma relação de mediação.

Dessa forma, resgata-se o elemento histórico do conceito de forças produtivas, livre de qualquer visão determinista. Cada sociedade em que predomina uma determinada relação de produção tem suas próprias forças produtivas, e a contradição entre forças produtivas e relações de produção pode ser apreendida como um aspecto do caráter contraditório das relações de produção vigentes em determinada situação histórica. 
A partir dessa conceituação de forças produtivas, têm-se as condições para compreensão da categoria tecnologia em Marx. Para se chegar a esse entendimento é preciso primeiramente expor as relações de produção capitalistas, apreendidas como um conjunto de relações: a relação mercantil e a relação capital-trabalho (Lipietz, 1988). Nas sociedades em que predomina a relação capital-trabalho, a forma de organização social da produção é a forma mercantil; a produção da sociedade se organiza por meio das relações entre proprietários privados ligados pela divisão social do trabalho. O produto toma então a forma de mercadoria e a relação social entre os produtores privados toma a forma de relação social entre mercadorias, a forma valor.

O pressuposto, sempre renovado, da relação capital-trabalho por sua vez, é a separação entre os produtores diretos e as condições de produção - meios de produção e meios de subsistência. Separada da propriedade dos meios de produção e dos meios de subsistência, a força de trabalho - o trabalho como potência — se torna mercadoria, pois só pode se tornar atividade quando unida às suas condições, isto é, quando vendida aos proprietários dessas condições. Uma vez alienada a força de trabalho, sua atividade e seu produto são apropriados pelos proprietários dos meios de produção (Balibar, 1980; Lipietz, 1988).

A separação entre trabalho e condições de trabalho, entretanto, só é completa quando o proprietário dos meios de produção se apropria de valor suficiente para não participar diretamente do processo de trabalho e para garantir a valorização do capital em escala ampliada. Essa condição define o caráter específico da produção capitalista, a forma social do processo de trabalho. O caráter social do processo de trabalho cria novas potencialidades humanas na transformação da natureza, constituindo, assim, as forças produtivas capitalistas. Mas essas potencialidades só podem ser acionadas após a venda das forças de trabalho, no momento em que o trabalho em potência se transforma em atividade e, portanto, são apropriadas pelo capital e postas a serviço de sua finalidade, a expansão do valor excedente (Marx, 2002, cap. 11).

A forma social do processo de trabalho apresenta-se duplamente como trabalho coletivo e trabalho universal. No processo de trabalho capitalista, os trabalhadores cooperam de forma direta no processo de produção, trabalhando simultaneamente no mesmo local para o mesmo capital, constituin- 
do um trabalhador coletivo. Se esse caráter coletivo é precondição para a apropriação do trabalho universal, esta por sua vez leva a novos limites a forma social do processo de trabalho.

Segundo Marx (1987, p. 116), o "trabalho universal é todo trabalho científico". Ao contrário do trabalho coletivo, o trabalho universal não pressupõe apenas a cooperação imediata, mas tem como condição também o uso dos trabalhos anteriores; os seus resultados são as descobertas científicas e as inovações. A incorporação do elemento universal na produção modifica inteiramente as bases técnicas do processo de trabalho e torna a tecnologia o princípio da organização da produção.

O processo de trabalho pré-capitalista era organizado em torno do ofício. O como fazer se originava do conhecimento empírico, da experiência; a melhor forma de produzir era transmitida e conservada de geração a geração. Entendida como princípio organizador da produção, a tecnologia consiste em "considerar em si mesmo cada processo de produção e de decompô-lo, sem levar em conta qualquer intervenção da mão humana, em seus elementos constitutivos"; dessa forma o processo de trabalho "se decompõe em aplicações da ciência conscientemente planejadas e sistematicamente especializadas segundo o efeito útil requerido" (Marx, 2002, p. 557). Assim, a tecnologia substitui a rotina empírica por princípios universais de conhecimento aplicados ao processo de produção, e o saber fazer do trabalhador imediato no processo de produção se torna secundário em face do conhecimento científico de caráter universal.

Marx apreende a tecnologia como a aplicação do conhecimento científico como princípio organizador da produção. Procura-se apresentar em seguida três desdobramentos, intimamente relacionados, dessa concepção da tecnologia: (i) seu caráter derivado das relações de produção capitalistas; (ii) o caráter constantemente revolucionário do processo de produção capitalista; (iii) a aplicação da ciência como princípio organizador da produção para além do instrumento de trabalho.

Para entender a relação entre a tecnologia e as relações de produção capitalistas é preciso retomar o aspecto fundamental dessa relação: a separação entre o trabalhador e as condições de trabalho. Essa separação caracteriza a relação entre capital e trabalho como uma relação de apropriação, conforme visto anteriormente. Mas, enquanto o trabalhador detém o saber 
fazer do processo de trabalho, enquanto o processo de trabalho depende das decisões, julgamentos e ações efetuadas pelo trabalhador na oficina, a posse do trabalho - isto é, o controle e a capacidade de organizar o processo de trabalho - ainda não pertence ao capital.

Se, por um lado, a relação de separação já se apresenta na constituição do caráter social do processo de trabalho em sua forma cooperativa - caráter esse estranho a cada trabalhador que aliena individualmente sua força de trabalho para o capital - a posse do processo de trabalho pelo capital só se constitui com o surgimento da tecnologia como princípio de organização do processo produtivo. A organização do processo de trabalho a partir da aplicação de princípios universais do conhecimento científico permite ao capital a organização da produção independente das capacidades previamente adquiridas pelos trabalhadores e da mobilização de seus recursos de julgamento e decisão.

As relações de produção capitalistas - incluída aqui a posse do processo de trabalho - tornam o trabalhador um elemento a mais no processo de produção, que pode ser adaptado às condições do processo de trabalho previamente definidas pelo capital. As potencialidades humanas que permitem a transformação da natureza em graus mais elevados são externas aos trabalhadores e se apresentam como opostas a eles; a tecnologia promove, assim, a objetivação do processo de trabalho.

A tecnologia não é apenas um conjunto de instrumentos para o controle da natureza, ela é também e fundamentalmente um instrumento para o controle do processo de trabalho pelo capital (Feenberg, 1992), por isso ela é portadora da relação entre capital e trabalho. A tecnologia como força produtiva é também uma relação de posse das forças produtivas pelo capital - aquilo que Marx denominou a subsunção real do trabalho ao capital (Balibar, 1980; Lipietz, 1988).

A tecnologia não só é portadora da relação de posse como também é parte da estrutura global do capital. A relação de propriedade separa os meios de produção dos trabalhadores, transformado-os, assim, em capital. Conforme assinala Mészáros:

Assim sendo, no que diz respeito à sua lógica imanente, os meios de produção já não são meios genuínos, mas uma parte determinada do capital que se autoimpõe. Como "meios de produção" eles representam uma forma especí- 
fica de capital. Entretanto, por constituírem apenas uma parte do capital em si estão sujeitos às determinações intrínsecas desse sistema produtivo como um todo (Mészáros, 2002, p. 664).

Dessa forma, a tecnologia está sujeita ao constrangimento imposto pela finalidade de expansão do capital e o controle da força de trabalho necessário para isso. Nesse sentido não há neutralidade instrumental dos meios de produção: “(...) os limites da neutralidade instrumental em relação aos instrumentos particulares do trabalho são decididos pela sua capacidade ou não de se tornarem parte constitutiva de um sistema global" (Mészáros, 2002, p. 865).

Tal constrangimento implica que o desenvolvimento e uso da tecnologia é extremamente seletivo. Assim, se existe mais de uma solução tecnológica para um problema de controle da natureza, a solução que for mais compatível com a expansão do capital e do controle do processo de trabalho será considerada como viável (Feenberg, 1992).

Esse constrangimento às necessidades de expansão do capital e controle do trabalho não se limita à tecnologia, mas crescentemente diz respeito à produção de conhecimentos, à própria ciência. A ciência se torna progressivamente vinculada aos objetivos da tecnologia, ao controle do processo de trabalho. Assim, a ciência se torna cada vez mais tecnociência (Vincent, 1990). Conforme assinala Mészáros:

(...) a atividade científica é praticamente orientada (e constantemente reorientada, quaisquer que sejam as ilusões da "ciência pura de desenvolvimento autonomo") em consonância com sua posição na estrutura da divisão capitalista do trabalho. Com isso visa a dupla tarefa de, por um lado, inventar mais e mais maquinaria produtiva "eficaz em relação ao custo" (o que quer dizer, primordialmente economizadora de trabalho), e, por outro, divisar os métodos e processos adequados para a lucrativa produção em massa de mercadorias (Mészáros, 2002, p. 667-668).

Ou ainda, como assinala Prado:

A matéria privilegiada do capital, aquela em que recai o grande investimento porque aí está a fronteira da acumulação e a fonte dinâmica da geração de lucros, é agora o próprio conhecimento científico e tecnológico (Prado, 2005, p. 126).

Cada vez mais os locais de produção do conhecimento são subsumidos direta ou indiretamente ao controle do capital (Vincent, 1990). A produção 
científica submissa ao controle do capital deixa de lado a produção de conhecimentos voltados para as necessidades humanas em prol da valorização do capital. Conforme assinala Mészáros:

(...) avanços no know-how científico podem ser agora transformados em meios de produção realmente empregados, não no terreno das (nem em resposta às) necessidades humanas, mas tão somente se seu procedimento favorecer aos interesses do sistema do capital (Mészáros, 2002, p. 663-664).

Um segundo ponto a ser considerado diz respeito ao desenvolvimento do processo de trabalho. A aplicação do conhecimento científico na produção e as relações de produção capitalistas resultam na mudança contínua do processo de trabalho. Primeiramente, a colocação do conhecimento científico na base da organização da produção leva à ampliação contínua da capacidade de transformação da natureza. Isso deriva do caráter relativo do conhecimento científico: novas propriedades da natureza podem ser descobertas a um nível cada vez mais fundamental, desdobrando-se em sua aplicação tecnológica.

Mas não se trata aqui apenas da natureza do conhecimento científico; trata-se fundamentalmente do caráter das relações de produção, isto é, a relação mercantil e a relação capital-trabalho em seu duplo aspecto de relação de propriedade e de posse.

Primeiramente, é preciso lembrar que o objetivo da produção capitalista é a acumulação, a transformação da mais-valia em capital em escala sempre ampliada. Uma vez estabelecida a posse do processo de trabalho pelo capital, isto é, uma vez efetuada a subsunção real do trabalho, a transformação do processo de produção se torna a principal forma de incrementar a maisvalia. Com os aumentos generalizados de produtividade e a diminuição do tempo de trabalho socialmente necessário para produção de uma unidade de mercadoria, o tempo de trabalho socialmente necessário - e consequentemente o valor - contido nas mercadorias que entram na reprodução do valor da força de trabalho diminui, caindo assim o valor da força de trabalho e aumentando o trabalho excedente através da obtenção de mais-valia relativa (Marx, 2002, cap. 10).

Deve-se assinalar que, na subsunção real, a mais-valia relativa se torna apenas forma predominante e de modo algum exclusiva de extração de trabalho excedente. A extração de mais-valia absoluta e outras formas 
de exploração continuam a ser praticadas pelo capital. Conforme assinala Mészáros,

(...) as diferentes seções do capital global podem operar com êxito, em plena cumplicidade umas com as outras, as práticas econômicas mais antiquadas e abertamente exploradoras (...) (Mészáros, 2002, p. 683).

Mas a transformação contínua dos processos de produção não pode ser atribuída somente à apropriação crescente de mais-valia; além da relação de apropriação, é necessário considerar também o controle do processo de trabalho. A objetivação e o controle do processo de trabalho pelo capital nunca são completos; a cada nova forma de controle do processo de trabalho novos meios de resistência são encontrados pelos trabalhadores. Em outras palavras, o controle do processo de trabalho é o campo de uma batalha contínua travada entre o capital e o trabalho, na qual a posse do processo de trabalho pelo capital está sempre sendo ameaçada pela resistência dos trabalhadores. Novos métodos de produção criam novas formas de controle e quebram antigas resistências.

A busca de incrementos crescentes de mais-valia e do controle do processo de trabalho, no entanto, tem seu impulso imediato nas relações entre os capitalistas. É preciso levar em conta que o capital existe como vários capitais que são produtores privados de mercadorias, isto é, só existe como ação mútua de capitais particulares, como concorrência. Obter maior lucro que os concorrentes através de métodos mais produtivos que diminuam os custos é o móvel primeiro para os capitais procurarem inovar continuamente o processo de produção (Marx, 2002, cap. 10).

Um terceiro ponto derivado da categoria tecnologia em Marx será considerado com mais detalhe: a aplicação da ciência como princípio organizador da produção para além do instrumento de trabalho. Esse será o objeto da seção seguinte.

\section{DA FISIOLOGIA À PSICOLOGIA: O HOMEM COMO OBJETO DA TECNOLOGIA}

No modo de produção capitalista se modifica a natureza dos meios de trabalho. De ferramentas sob o controle do trabalhador os meios de trabalho passam a se constituir em máquinas. Nas máquinas as ferramentas que 
atuam diretamente sobre o objeto de trabalho estão acopladas a um mecanismo que lhes confere movimento, determinando seu ritmo, força e direção independente da ação dos trabalhadores (Marx, 2002, cap. 13).

A tecnologia abrange todos os outros aspectos do processo de trabalho: os objetos de trabalho, os produtos e a própria força de trabalho. A transformação da força de trabalho pela tecnologia se dá indiretamente pela mecanização, mas também de forma direta pela aplicação de princípios científicos no controle e na transformação do próprio trabalhador, conforme será desenvolvido nesta seção.

A mecanização torna a habilidade e destreza dos trabalhadores um elemento secundário na produção. Rompendo a unidade entre o trabalhador e sua ferramenta, a maquinaria passa a ser o elemento determinante do como fazer no processo de trabalho. Em um processo que é determinado pelos meios de produção, o elemento humano, subjetivo, se encontra subordinado aos elementos objetivos; em outras palavras, a mecanização é o meio pelo qual se efetiva a objetivação do processo de trabalho.

A transformação dos meios de produção em máquina resulta da aplicação consciente das ciências físicas e também da química. O conhecimento científico, porém, não é restrito apenas ao mundo físico; o homem em suas dimensões física, social e psicológica também se tornou objeto da ciência. A aplicação consciente dos princípios da biologia e da psicologia à produção torna o homem um objeto da tecnologia.

Alguns dados relativos à história da ciência permitem situar o surgimento do corpo, da vida e do comportamento humano como objetos da ciência em meados do século XIX. Em 1830 se instalou o primeiro laboratório de fisiologia experimental na França, dando início à medicina moderna. $\mathrm{O}$ estudo de Darwin sobre a evolução das espécies se inicia na década de 1830 e tem sua plena divulgação e desenvolvimento com a publicação da Origem das espécies em 1858 e em trabalhos posteriores. Em 1865 são divulgados os estudos de Mendel que inaugurariam a genética, cujo pleno desenvolvimento ocorreu no século XX. Finalmente, deve-se lembrar a fundação da psicologia científica com a obra de Fechner em 1860 e posteriormente com a inauguração, por Wundt, do primeiro laboratório de psicologia experimental em 1879 (Châtelet, 1983).

O homem em suas dimensões fisiológica, biológica e psicológica se torna objeto da investigação científica a partir da segunda metade do século XIX. 
É também nesse período que os primeiros experimentos de Taylor com a gerência científica inauguram a tecnologia aplicada ao homem no processo de trabalho. Os princípios básicos do taylorismo consistiam na separação entre a concepção e a execução e na determinação do modo de execução pela gerência. $\mathrm{O}$ seu instrumento fundamental consistia no estudo dos tempos e movimentos (Braverman, 1987; Coriat, 1982).

Uma análise empírica dos movimentos dos trabalhadores deveria preceder a determinação do modo de execução pela gerência. Através dessa análise seria possível eliminar movimentos inúteis e descobrir o melhor movimento para executar uma operação em menor tempo. A partir desse estudo determinavam-se as tarefas que especificavam os movimentos e seu tempo de execução pelos trabalhadores (Braverman, 1987; Coriat, 1982).

O estudo empírico dos tempos e movimentos não permite apreender o taylorismo como uma tecnologia, uma vez que em cada processo de trabalho e a cada reorganização deste o ponto de partida deve ser a observação do trabalhador em ação. Entretanto, o estudo dos tempos e movimentos ganha o caráter de aplicação de princípios científicos universais a partir do momento em que se fundamenta em uma análise dos movimentos básicos do corpo humano - andar, levantar, girar etc. — apoiada na fisiologia (Braverman, 1987). Dessa forma, o taylorismo consiste em uma aplicação consciente da ciência no processo de trabalho tendo como objeto a corporeidade do trabalhador e sendo, em sua universalidade, aplicável a qualquer processo de trabalho, independente do grau de mecanização ou da natureza do produto.

O taylorismo inaugura, então, uma outra dimensão da tecnologia. Se a transformação dos meios de trabalho em máquina promove a objetivação do trabalho - a subordinação do elemento humano, subjetivo aos elementos objetivos -, o taylorismo traz à tona a dessubjetivação do trabalho $o^{1}$ - a transformação do elemento humano em objeto manipulável a partir da aplicação da ciência ao processo de trabalho. ${ }^{2}$

Deve-se notar que a dessubjetivação do trabalho só é compreensível a partir do conceito de tecnologia estabelecido na seção anterior. Se a tecnologia for entendida apenas como um conjunto de instrumentos neutros, ela será incompatível com a manipulação dos homens no processo de trabalho por meio da ciência, sua posição como objeto da tecnologia. 
O taylorismo contempla apenas uma dimensão do elemento humano, a sua corporeidade entendida como mecanismo. O prosseguimento da dessubjetivação do processo de trabalho se deu pela consideração de outros aspectos do elemento humano; em outras palavras, a consideração da dimensão psicológica do ser humano. Hugo Mustenberg, em Psychology and industrial efficiency (1913), foi o primeiro a perceber isso e a tentar corrigir a visão unilateral do taylorismo, colocando a psicologia "a serviço do comércio e da indústria” e inaugurando a psicologia industrial, que tem claramente o caráter de tecnociência.

Os métodos para a seleção científica dos trabalhadores propugnada por Taylor e os efeitos de fadiga e insatisfação decorrentes da aplicação dos princípios tayloristas trouxeram à tona um conjunto de questões cujas respostas foram buscadas nas teorias do comportamento humano. ${ }^{3}$ Já na década de 1930 os estudos empíricos de Hawthorne e Elton Mayo enfatizavam o papel dos grupos informais no comportamento dos trabalhadores inaugurando a escola das relações humanas na administração. Indo além da gerência científica taylorista, a escola das relações humanas procura compreender as motivações e relações interpessoais como fatores determinantes do desempenho no trabalho.

Os estudos de Alfred Maslow (1943) sobre as motivações humanas e de Kurt Lewin ${ }^{4}$ sobre o funcionamento dos grupos e os estilos de liderança ampliaram o conhecimento acerca do comportamento humano e possibilitaram novas aplicações da ciência do comportamento ao processo de trabalho. Tais estudos, dentro da ideia geral da escola das relações humanas, colocam a ênfase na cooperação, na responsabilidade, na satisfação e no status no grupo como elementos determinantes do desempenho no trabalho.

A aplicação da teoria do comportamento no processo de trabalho levou à difusão no final do século XX de formas de organização aparentemente opostas ao taylorismo. Deve-se ressaltar que os condicionantes dessa difusão não se originam apenas na evolução da ciência do comportamento humano. Os determinantes das mudanças no processo de trabalho apontados na seção anterior também se fizeram presentes na difusão das novas formas de organização do processo de trabalho que vieram a substituir o taylorismo. Sumariamente, podem-se destacar entre os referidos determinantes o esgotamento dos ganhos de produtividade dos métodos tayloristas e, espe- 
cialmente, a resistência dos trabalhadores, desde a "microrresistência" que aparece como absenteísmo e alto grau de rotatividade até as grandes greves que reivindicavam maior autonomia no processo de trabalho (Coriat, 1982).

As novas formas de organização do processo de trabalho substituem o princípio taylorista de um homem para uma tarefa pela organização do processo do trabalho com base em equipes e em tarefas redefiníveis e recompostas, criando o trabalhador multifuncional e polivalente e com a atribuição de maior autonomia e responsabilidade ao trabalhador. Embora tais técnicas "flexíveis" de organização de trabalho sejam bastante diferentes das técnicas tayloristas, o que está em jogo é um desenvolvimento do processo de dessubjetivação do trabalho, tendo agora como objeto o elemento consciente da produção.

Mesmo com elementos como responsabilidade, criatividade e autonomia passando a fazer parte da organização do processo de trabalho, seu objetivo continua sendo o mesmo do taylorismo, a busca da eficiência. Permanecem a intensificação do trabalho, a atribuição de tarefas e a análise dos tempos e movimentos. ${ }^{5}$

As novas formas de organização do trabalho têm sido entendidas como um processo que leva à hegemonia do trabalho imaterial. $\mathrm{O}$ trabalho imaterial é entendido como "trabalho que produz um bem imaterial, como serviço, produto cultural, conhecimento ou comunicação" (Hardt e Negri, 2001, p. 311), ou ainda como o trabalho que produz o conteúdo informacional e cultural da mercadoria (Lazzarato, 1992). Independente de resultar em uma mercadoria tangível ou não, o trabalho imaterial se caracterizaria como aquele no qual são mobilizadas as capacidades comunicacionais, intelectuais e afetivas dos trabalhadores (Hardt e Negri, 2001, p. 314).

A tese do trabalho imaterial se apoia em uma suposta subjetivação do trabalho após a tentativa taylorista fordista de transformar o trabalho vivo em um mecanismo. No pós-fordismo, o trabalho vivo ganharia importância e sua natureza teria sido transformada para um trabalho com conteúdo. A força de trabalho se constituiria como social e autônoma agindo como sujeito ativo na coordenação comunicacional em lugar de obedecer à imposição da gerência (Lazzarato e Negri, 1991). A cooperação do trabalho não seria mais posta pelo capital, mas, sim, pressuposta pelo trabalho imaterial 
(Hardt e Negri, 2001; Lazzarato, 1992). A implicação da subjetividade e a cooperação espontânea do trabalho resultariam que o capital não se apresenta mais como sujeito da produção (Lazzarato, M. 1992). De acordo com esses autores, o capital é que teria de se adaptar ao trabalho. Assim,

Le processus de production de subjectivité, c'est-à-dire le processus de production tout court, se constitue «hors» du rapport au capital, «au sein» des processus constitutifs de l'intellectualité de masse, c'est-à-dire dans la subjectivation du travail (Lazzarato e Negri, 1991, p. 95).

Em resumo, a tendência de hegemonia do trabalho imaterial resultaria na abolição do trabalho estranhado. ${ }^{6}$

A dessubjetivação do trabalho apresentada neste artigo nos remete na direção oposta à tese do trabalho imaterial nesse aspecto. A dessubjetivação do trabalho reforça o caráter estranhado do processo de trabalho. No processo de produção capitalista, a exteriorização do trabalhador no seu produto passa a significar a autonomia e hostilidade de uma potência estranha. O produto se determina não só como externo, mas também como hostil e estranho. O processo de trabalho capitalista não é um processo no qual o trabalhador se afirma; o trabalho não é um meio de realização do trabalhador, mas de sua negação. $\mathrm{O}$ trabalho aparece como atividade independente e hostil que pertence a outro. A atividade vital do trabalhador é um meio para sua existência, e não um fim em si mesmo no qual se afirma sua essência (Marx, 2004).

A dessubjetivação do trabalho é um processo de negação do elemento subjetivo; pelo processo de dessubjetivação o trabalhador é transformado de sujeito em coisa. Se essa transformação já é dada pela simples venda da força de trabalho, seu caráter é aprofundado na medida em que o trabalhador se torna um objeto manipulável pela ciência. Assim, a desssubjetivação do trabalho torna a atividade do trabalhador algo em que esse se vê negado como sujeito. Através da dessubjetivação as potencialidades subjetivas do trabalhador se apresentam como independentes e hostis a ele, como pertencentes a um outro. A dessubjetivação reforça o caráter hostil e estranho que o processo de trabalho tem na produção capitalista ao reduzir os elementos subjetivos ao estatuto de coisa.

Assim, ao contrário do que afirmam os proponentes do trabalho imaterial, o trabalhador não é o sujeito ao qual o capital se adapta. Os trabalhado- 
res ainda vendem sua força de trabalho para o capital, e é este que põe a sua valorização como finalidade do processo. O processo de trabalho continua sob o controle do capital como sujeito, atendendo às necessidades de sua reprodução, e não às necessidades humanas conscientemente postas pelos produtores, e por isso ainda é uma atividade estranha para o trabalhador. Conforme afirma Prado: "Nos limites do capitalismo, o trabalhador continua não determinando os fins de sua atividade, não se torna sujeito de sua própria atividade produtiva, (...)” (Prado, 2005, p. 125-126).

As características subjetivas do trabalho só são mobilizadas na medida em que atendem aos interesses do capital. Além disso, os elementos subjetivos são induzidos por técnicas manipulatórias aprendidas pelos gerentes nas escolas de administração; a aparente emergência da subjetividade no processo de trabalho surge como apropriação dos elementos subjetivos pelo capital através das "tecnologias do comportamento".

Com os métodos pós-fordistas de organização do trabalho, o caráter estranho e hostil para o trabalhador do processo de trabalho ganha uma outra forma: o controle sobre o processo de trabalho deve ser internalizado pelos trabalhadores ao ponto de estes terem de se ver como empreendedores de si mesmos ou como participantes de uma "comunidade harmoniosa", a empresa. A empresa,

exige la devoción incondicional y personal de cada uno a los fines de la empresa e instrumentaliza a toda la persona - sus facultades linguisticas, su capacidad de aprender, de prever, de analizar etcétera - en función de ésta. La empresa "compra ante tudo a la persona e su devoción" y no desarrolla sino a continuación "la capacidad de trabajo abstracto" de ella. Da forma y condiciona a esta persona y "reduce su horizonte al de la fábrica". La subjetividad que se despliega alli es lo contrario de una subjetividad libre (...) (Gorz, 2003, p. 48).

Assim, a dessubjetivação do trabalho pós-fordista significa que o próprio trabalhador, e não somente o trabalho, se submete subjetivamente ao capital; os meios de controle não estão mais incorporados somente aos meios de produção, mas procuram atingir a própria identidade do trabalhador. Trata-se, portanto, da sujeição da própria subjetividade.

La dominación del capital (...) No puede ejercerse más que tomando caminos indirectos: debe desplazarse por encima de la fábrica y tomar la forma de un condicionamiento que conduce al sujeto a aceptar o a elegir precisamente eso 
que se entiende que le impone. La fábrica, el lugar de trabajo, dejan entonces de ser el terreno principal del conflito central. El frente se va a encontrar (...) en todos los lugares, (...) donde la subjetividad, "la identidad" de los individuos, sus valores, sus imágenes de sí mismos y del mundo son perpetuamente estructurados, fabricados, formados (Gorz, 2003, p. 52).

A análise e a identificação desse processo de dessubjetivação do trabalho são incompletas caso não se atente para seu limite, que pode ser sintetizado em um "paradoxo da dessubjetivação do trabalho". Tal paradoxo pode ser apreendido pelo fato de que a dessubjetivação do trabalho, a apropriação da subjetividade do trabalhador pelo capital no processo de trabalho, pressupõe a própria negação do elemento constitutivo fundamental da subjetividade, a autonomia. A condição para o processo do trabalho capitalista são a venda da força de trabalho, sua alienação para o capital e, portanto, a negação de qualquer autonomia na definição da finalidade do processo de trabalho; assim, o trabalhador responsável e criativo dos novos processos de trabalho é "livre para realizar os fins de um amo, mas só para isso" (Gorz, 2003, p. 53). Patentea-se, assim, um paradoxo que revela os limites da dessubjetivação do trabalho: o capital, no processo de trabalho, só pode se apropriar de uma subjetividade vazia de seu elemento definidor, a autonomia.

\section{CONSIDERAÇÕES FINAIS}

Procurou-se neste trabalho avançar uma interpretação da obra de Marx que esteja liberta do determinismo tecnológico tão caro ao marxismo soviético e presente ainda hoje em autores como Cohen (1989). Na leitura apresentada os conceitos de forças produtivas e relações de produção se determinam mutuamente, as forças produtivas são portadoras da relação de posse e participantes da totalidade do capital, sendo assim impossível tratar a natureza das forças produtivas e seu desenvolvimento sem considerar as relações de produção vigentes.

Essa leitura permite compreender a tecnologia, a aplicação do conhecimento científico como princípio organizador da produção, como forma de desenvolvimento das forças produtivas nas sociedades em que predominam as relações capitalistas. Um dos elementos distintivos das relações de produ- 
ção capitalista é a forma social do processo de trabalho e sua apropriação pelo capital; essa apropriação chega ao seu ponto mais elevado com a apropriação do trabalho universal, produtor das descobertas científicas. A apropriação da ciência pelo capital institui a tecnologia como princípio organizador da produção, e todos os elementos do processo de trabalho - incluindo a própria força de trabalho - se tornam passíveis de recomposição e transformação pelo capital.

Essa compreensão das forças produtivas e da tecnologia resolve o dilema entre sistema técnico e organização do trabalho; na produção capitalista não se trata de adequar a organização do trabalho ao sistema técnico. O que está em jogo aqui, em um nível mais profundo, é a transformação do processo de produção pela tecnologia, transformação essa que consiste nos processos complementares de objetivação e dessubjetivação do processo de trabalho.

\section{NOTAS}

1. Trata-se de um neologismo. O prefixo des indica a ideia de separação e negação; o termo dessubjetivação significa o processo de negação do elemento subjetivo no processo de trabalho, diferente do processo de sua subordinação ao elemento objetivo contida no conceito de objetivação.

2. A interpretação desenvolvida nesse ponto se assemelha à apresentada por Paulani, (2001). A autora utiliza uma conceitualização hegeliana para interpretar as mudanças no processo de trabalho desde a mecanização até as novas formas de organização do trabalho.

3. Neste trabalho utiliza-se a expressão teorias do comportamento referindo-se às teorias que procuram explicar o comportamento humano observável para se diferenciar das teorias psicológicas, como a de Freud e William James, que buscam explicar o que é a consciência.

4. O trabalho de Kurt Lewin é um bom exemplo da autonomia relativa da ciência; sua teoria sobre a dinâmica de grupos e da action research serviu de base para vários grupos políticos radicais na década de 1960 (Smith, 2001).

5. Uma notável exceção nesse aspecto, notada em toda a literatura, é a fábrica da Volvo em Udevalla, fechada em 1993, em que o grau de autonomia dos trabalhadores no processo de trabalho foi muito maior do que em outros casos.

6. Uso o termo estranhamento como tradução do alemão entfremdung no lugar de alienação. Da mesma forma utilizo o termo trabalho estranhado no lugar de trabalho alienado e estranho e estranhado no lugar de alienado. Ver Marx (2004, p. 15-16). 


\section{REFERÊNCIAS BIBLIOGRÁFICAS}

BALIBAR, E. Sobre os conceitos fundamentais do materialismo histórico. In: ALTHUSSER, L. et al. Ler o Capital. Rio de Janeiro: Zahar, p. 153-274, 1980.

BRAVERMAN, H. Trabalho e capital monopolista. A degradação do trabalho no século XX. Rio de Janeiro: Guanabara, 1987.

CHÂTElET, F. (Org.) História da filosofia, v. 6 e 7. Lisboa: Publicações Dom Quixote, 1983.

COHEN, G. A. Fuerzas productivas y relaciones de producción. In: ROEMER, J. E. (Org.) El marxismo: una perspectiva analítica. México: Fondo de Cultura Económica, 1989.

CORIAT, B. El Taller y el Cronometro. Ensayo sobre el taylorismo el fordismo y la producción en masa. México: Siglo veinteuno, 1982.

FEENBERG, A. Subversive Rationalization: technology, power and democracy. In: Inquiry, 35, $3,1992$.

—. Transforming Technology: a critical theory revisited. Oxford, 2002.

GORZ, A. Miserias Del presente, Riqueza De Lo Posible. Buenos Aires: Paidós, 2003.

HARDT, M.; NEGRI, T. Império. Rio de Janeiro: Record, 2001.

LAZZARATO, M. Lê concept de travail immatériel: la grande entreprise. In: Futur Antérieur, n. 10, 1992.

-; NEGRI, T. Travail immatériel et subjectivité. In: Futur Antérieur, 6, 1991.

LIPIETZ, A. From althusserianism to regulation theory. In: KAPLAN, A. E.; SPRINKER, M. The Althusserian Legacy. Londres; Nova York: Verso, 1993. Disponível em: http://lipietz.net.

Reflexões sobre uma fábula: por um estatuto marxista dos conceitos de regulação e de acumulação. In: Dados: Revista de Ciências Sociais, Rio de Janeiro: Iuperj, v. 31, n. 1, p. 1-139, 1988.

MARX, K. Manuscritos econômico-filosóficos. São Paulo: Boitempo, 2004.

O capital: crítica da economia política; livro I. Rio de Janeiro: Civilização Brasileira, v. 2, 2002.

O capital: crítica da economia política; livro III. São Paulo: Difel, 1987.

. Teses sobre Feubarch. In: MARX, K. A ideologia alemã. São Paulo: Hucitec, 1987a.

MASLOW, A. A theory of human motivation. In: Psychological Review, 50, 1943. URL: http:// psychclassics.yorku.ca/Maslow/motivation.htm (acessado em 26 nov. 2004).

MÉSZÁROS, I. Para além do capital: rumo a uma teoria da transição. São Paulo: Boitempo, 2002.

MUNSTERBER, H. Psychology and Industrial Efficiency. URL: http://psychclassics.yorku.ca/ Munster/Industrial/ (acessado em 26 nov. 2004).

PAULANI, L. M. O papel da força viva de trabalho no processo capitalista de produção: uma análise dos dilemas contemporâneos. In: Estudos Econômicos. São Paulo, v. 31, n. 4, out.dez. 2001. 
PRADO, E. Desmedida do valor: crítica da pós-grande indústria. São Paulo: Xamã, 2005.

SMITH, M. Kurt Lewin: groups, experimental learning and action resarch, 2001. URL: http:// www.infed.org/thinkers/et-lewin.htm\#actionresearch (acessado em 26 nov. 2004).

VINCENT, J. M. Capital et Technoscience. In: Futur Antérieur, 3, automne 1990. 